\title{
Social Status and Peer-Punishment: Findings from Two Road Traffic Field Experiments
}

\begin{abstract}
In a seminal experiment, Doob and Gross (1968) examined the influence of social status on peer-punishment of norm violations in traffic. They observed an inverse relationship between the economic status indicated by a car that was blocking an intersection and the punishment meted out to the driver of that car, with "punishment" taking the form of a honk of the car horn. In a more recent experiment, Diekmann et al. (1996) noted the status and reactions of the cars blocked by a single midstatus car. Blocked drivers at the wheel of a higher-status car were found to punish more aggressively than drivers of a lower-status car. Our study employs a combined design to separate the effects of driver and blocker status. In two field experiments, we varied the status of the norm-violating car and recorded the status of the blocked driver's (i.e., the experimental subject's) car. Our results provide evidence that social distance facilitates peer-punishment. Punishment was expressed less readily when the blocked and blocking cars indicated a similar social status.
\end{abstract}

\section{Introduction}

Various studies have examined the relationship between socioeconomic status and the peer-sanctioning of norm violations (such as unnecessarily blocking the way) in road traffic. Most of these have focused on the effect of the status of only one of the parties, either that of the norm violator or that of the punisher. In a seminal study examining the effect of the norm violator's status, Doob and Gross (1968) measured horn-honking response times as an indicator of drivers' aggression in response to being blocked by an experimental car at traffic lights in the United States. Two different blocking cars were used, each indicating a different social status. As response times were significantly shorter, and responses occurred significantly more frequently, when a driver was frustrated (i.e., blocked) by an automobile indicating lower status, Doob and Gross concluded that the presumable social status of the blocking driver and aggression expressed toward that blocking driver are inversely related. Deaux (1971) found a similar yet non-significant effect in one roughly contemporaneous replication

\footnotetext{
Note: We are indebted to Renato Marioni and Stephan Suhner (Experiment 1), and to Jörg Rothe, Heiko Schmiedeskamp, Hélène Venningen, Jelena Curcic, and Jakub Swiech (Experiment 2), for their support in designing the experiments, conducting the fieldwork, and/or preparing the data. We thank BMW (Schweiz) AG for providing a vehicle (free of charge) for Experiment 2. Experiment 1 has also been reported in Jann, Suhner, and Marioni (1995) and in Jann (2009); Experiment 2 has also been reported in Rothe and Schmiederkamp (2006).
}

https://doi.org/10.1515/9783110472974-013 
of the experiment in the U.S., but Chase and Mills (1973) found the opposite effect in another such replication. The effect reported by Doob and Gross was, however, recently replicated in a Japanese study that found longer honking latencies in response to being blocked by a high-status car than a low-status car, as long as the car did not display a beginning driver's plate (Yazawa 2004). Finally, drivers in a study by McGarva and Steiner (2000) responded more aggressively to provocation from a lowstatus driver than from a high-status driver.

Other studies have instead looked at the effect of the blocked driver's status on a honking response. For example, Diekmann et al. (1996) also blocked drivers at traffic lights (in Germany) and recorded horn-honking response times, but held the status of the blocking car constant while measuring the status indicated by the blocked car (containing the potential punisher). Diekmann et al. found a positive relationship between the status of the driver and the degree of aggression he or she displayed toward the driver of the blocking car (with the exception of the lowest class drivers, who acted fairly aggressively as well).

Results from such horn-honking studies are traditionally discussed in the context of theories of aggressive behavior. The idea is that being blocked causes frustration and anger on the side of the blocked driver (Baron 1976; Lajunen and Parker 2001; Lajunen, Parker, and Stradling 1998; Lawton and Nutter 2002), who may then react with responses such as horn honking, obscene gestures, flashing high beams, or tailgating (Hennessy and Wiesenthal 1997; Parker, Lajunen, and Summala 2002; Turner, Layton, and Simons 1975). Whether such behavior is shown depends on both the aggressor's traits and the situation in which the aggression occurs (for a corresponding general aggression model, see Anderson and Bushman 2002; for a similar model applying specifically to driver behavior, see Shinar 1998). A distinction is also made between hostile aggression as an impulsive response intended to harm a victim, and instrumental aggression, which is a premeditated action used as a means to achieve some goal other than harming a victim (Anderson and Bushman 2002:29). Although drivers who engage in horn honking are also likely to engage in other forms of mild aggression (Novaco 1991; Shinar 1998) and horn-honking behavior varies according to factors that have been observed to promote aggressive responses in general (such as uncomfortably hot temperatures, stressful circumstances, or increased anonymity: see Baron 1976; Kenrick and MacFarlane 1986; Hennessy and Wiesenthal 1999; Ellison et al. 1995), it seems obvious that honking often has an instrumental component, that is, the attempt to motivate the blocker to move his or her car. However, whether honking represents an expression of hostile or of instrumental aggression (which can be difficult to separate, as is pointed out by various authors: see Doob and Gross 1968; McGarva and Steiner 2000; Shinar 1998), there is reason to believe that drivers blocked at an intersection by an experimental car will find the experience frustrating and are likely to retaliate by honking their own car horns.

An explanation for why blocked drivers honk their horn is that the frustrating situation makes them angry. Anger has been defined as an attempt to adjust social behav- 
ior when someone else has violated rules or norms. It is an emotional state that often results in aggressive behavior, and may indeed be associated with aggressive behavior while driving (Lawton and Nutter 2002). There are, however, differences between people in terms of their disposition toward becoming angry, both in general (Pitkänen 1973; Verona, Patrick, and Lang 2002) and in response to frustrations on the road (Deffenbacher et al. 2001; Deffenbacher, Oetting, and Lynch 1994; McGarva and Steiner 2000; Yagil 2001). Anger is expressed less often than it is experienced, both while driving (Lajunen and Parker 2001) and in general (Ramirez, Santisteban, Fujihara, and Van Goozen 2002). One factor thought to influence the experience and the expression of anger is the social status of the angered person. Various theorists have discussed the role of emotional expression and suppression in establishing and maintaining social hierarchies (Clark 1990; Keltner, Gruenfeld, and Anderson 2003; Kemper 1978; Kemper 1987; Lovaglia and Houser 1996; McKinnon 1994; Ridgeway and Johnson 1990; SmithLovin 1990), predicting that those who occupy higher status positions will experience less negative affect than those of lower status and will also express any anger they experience more freely. There is some empirical evidence that this is the case. Using broad-based population samples, Haukkala (2002) and Schieman (2003) found either no SES-related differences in trait anger (Haukkala) or less anger in higher economic classes (Schieman). However, both authors found that anger, when experienced, was more likely to be expressed by those with better education or higher income. Other studies have found similar effects on the expression of anger in the workplace, with those of higher occupational status more likely to express their anger than those of a lower occupational status, although those with lower status often report experiencing more anger at work (Lively 2000; Sloan 2004). ${ }^{1}$

These results correspond with those showing a better fit between emotion and behavior (or less inhibited behavior) in high-status individuals, whether that higher status occurs naturally or has been experimentally produced (Anderson and Berdahl 2002; Hecht and LaFrance 1988; Keltner, Gruenfeld, and Anderson 2003). One study (Galinsky, Gruenfeld, and Magee 2003) artificially varied the status of subjects within their experimental groups, and found that participants of greater status were quicker to stop an irritating noise than those of lesser status. The proneness of high-status individuals to act in accordance with their emotions or wishes may also be reflected in more insistent driving techniques. For example, Taubman-Ben-Ari, Mikulincer, and Gillath (2004) found that placing high value on a driving style that reflected behaviors such as honking and flashing high beams at other drivers ("angry driving”) was positively associated with higher scores on Burger and Cooper's (1979) Desirability for Control scale. In other words, those who agreed with statements such as "I would

1 There is evidence that anger expression differs by social group, and also that people use the emotion expressed in a reaction to a trying or frustrating situation as a cue to an actor's social status. A higher status is ascribed to the person with the angry reaction (Conway, DiFazio, and Mayman 1999: Study 2; Tiedens 2001; Tiedens, Ellsworth, and Mesquita 2000). 
prefer to be a leader than a follower" and disagreed with statements such as "Others usually know what is best for me" also reported more honking and light-flashing behavior while driving.

There is, however, reason to believe that the relevant determinant of the expression of anger or irritation is less the status of the angered person than the difference in status between the angered person and the person who angered him or her. Some empirical evidence indicates that aggression "flows downward" in the status chain. For instance, subjects in Kuppens, Van Mechelen and Meulders' (2004) experiment reported being more likely to express anger toward a target of lower relative status than toward one of higher relative status, a result also obtained by Allan and Gilbert (2002). Using a probability sample of the U.S. population, Sloan (2004) found that workers were more likely to express anger toward their subordinates than toward their supervisors. Such results are also consistent with evidence from various animal studies on the establishment and maintenance of social hierarchies, in which aggression is found to flow downward (Barroso, Alados, and Boza 2000).

Alternatively, sanctioning behavior in road traffic may reflect a more general phenomenon of lower intra-group aggression or higher inter-group aggression. One mechanism for such an effect is a greater willingness to cooperate and a reduced propensity to aggress against actors whom one perceives as belonging to the same group. Research on social categorization and inter-group behavior (Billig and Tajfel 1973; Brewer and Kramer 1985; Mummendey and Schreiber 1983; Robinson 1996; Tajfel 1982a; Tajfel 1978; Tajfel 1982b; Tajfel et al. 1971; Turner, Brown, and Tajfel 1979) has revealed a strong bias toward favoring the in-group in many contexts - importantly, even "[...] in the absence of comparison with any other groups" (Brewer 1979:321; also see Kramer and Brewer 1986). In-group favoritism implies that aggression "flows outward".

There are also arguments for the reverse effect: that is, that aggression "flows inward". Gould (2003) argues that conflict occurs less often in relationships in which there is a clear hierarchy than in "symmetrical relationships". The reason is that people have a strong tendency to battle out a ranking if their positions are ambiguous due to the lack of an established hierarchy.

Whichever of these hypotheses applies, if the punishing behavior can be predicted from the difference in status between two parties to a conflict, previous studies on horn-honking responses have examined only one half of the equation. Some, such as the study conducted by Doob and Gross (1968), found that low-status blocking cars elicited faster reactions and thus higher levels of sanctioning than high-status blocking cars. Studies such as the one from Diekmann et al. (1996) report that high-status drivers reacted more quickly to having their progress impeded than low-status drivers. In the current study, we investigate a possible interaction effect between the status of the blocker and the status of the frustrated driver. We assume that the disparity between the statuses of the actors (rather than the status of one or the other per se) determines the aggressiveness displayed in the blocked-intersection situation. 
With respect to the various hypotheses about how the status differences matter, we conjecture that all of them might be true, but that they apply to different situations. For example, in a setting where there is competition for hierarchical positions, one could assume with Gould (2003) that most aggression occurs among actors with ambiguous positions. Likewise, in a situation in which lower status actors depend on higher ranking actors, such as in a workplace setting where the latter can exercise power over the former, aggression may "flow downward". Conversely, the underdogs may rebel against the oppressors, if given a chance to do so: that is, if the situation is such that they do not have to fear further repression. In this case, aggression would "flows upward". In the situation of blocked vehicles under study, however, we believe that the status indicated by the cars of the two drivers mostly functions as a device for social categorization, giving rise to the mechanisms of in-group favoritism. Hence, we assume that sanctioning behavior "flows outward": that is, sanctioning behavior is expressed more readily if the status between the two actors is different, independent of the direction of the difference. Note, however, that the same pattern could also result if, for example, higher status drivers punish lower status drivers because they feel more entitled to use the road, and, at the same time, the "underdogs" take the chance to rebel because they can do so without fearing retaliation.

\section{Methods}

\section{Experiment 1}

We blocked cars at traffic lights using an experimental car and measured hornhonking response times in a similar manner to Doob and Gross (1968). A pre-test was conducted to practice the blocking method and test our ability to capture the relevant information on our experimental subjects validly and reliably. Our experiment was conducted on two consecutive Saturday mornings in spring 1995 at an intersection with relatively light traffic in Bern, Switzerland. On the first Saturday we used an experimental car indicating a high social status (a black 1995 Audi A6 2.6L), and on the second a car indicating a low social status (a blue 1989 Volkswagen Golf C1 Mark III). Traffic conditions were similar on both mornings. As in other studies, the use of this method reflects the presumption that the car driven by a subject is (to some degree) assumed by the drivers of other cars to reflect his or her social status (Marsh and Collett 1986 provide evidence that this is the case). It also assumes that other subjects are able to perceive information such as the make of an automobile, which seems reasonable since drivers appear to note a wide variety of information about other drivers spontaneously (Knapper and Cropley 1980).

An experimental trial was initiated only when the experimental car could be stopped as the first car in a line formed at a red light, and when it was followed by just 
one car, whose driver's behavior was being recorded. ${ }^{2}$ After the light turned green, the experimental car remained stopped until the driver in the car behind it honked. The experimental car contained a driver and two visible observers, all male. One of the observers measured the time between the light's changing and the honking response. Using the mirrors, the other observer noted some information about the blocked subject, including the sex and estimated age of the driver, as well as the make, model, and status indicated by the blocked vehicle (in terms of one of three hierarchical categories based on the car's make, model, and approximate age). If a blocked subject did not respond within the twelve-second period during which the light was green, the case was considered censored at $t=12$. In total, 123 valid cases were observed, approximately 60 on each of the mornings, of which 26 represented censored measurements.

\section{Experiment 2}

In the second experiment, we blocked cars in a one-way street with relatively light traffic in the inner city of Zurich. We placed the experimental car approximately 30 meters down the road from the entry into the street, positioned slightly diagonally so that approaching vehicles could not pass and that the diver of the blocking car could be seen. After conducting several pretests, our experiment was carried out on a sunny Tuesday, between 10:30 a.m. and 5:40 p.m., in summer 2005. We used two experimental cars, one indicating high social status (a dark silver 2005 BMW 530i limousine; selling price 64,000 CHF) and one indicating low social status (a silver 1995 VW Golf 1800 Rolling Stones; selling price $24,000 \mathrm{CHF}$ ). Cars were switched about every 20 trials. We also varied the sex of the driver in the blocking car, switching drivers about every 10 trials. Since traffic conditions and temperature changed during the day, we control for temperature and traffic density in the analyses below. ${ }^{3}$

An experimental trial was initiated when a vehicle entered the street after the experimental car was in position. The experimental car remained stopped until the blocked car (or one of the subsequent cars, if several vehicles entered the street) honked. Each trail was taped by two video cameras, one hidden below a piece of clothing in the back of the experimental car and one operated by a confederate hiding in a hedge on the side of the street. Two further confederates, one on each side of the street, took notes about the blocked car, its driver, and the horn honking reaction using standardized forms (including information such as the time until the horn was

2 All trials were conducted at the same intersection between a main street and a side street. The trials were conducted in the side street, alternating the direction between each trial.

3 Temperature data for Zurich (one measurement every 10 minutes) was obtained from MeteoSwiss (Federal Office of Meteorology and Climatology). Information on hourly traffic flow (number of vehicles counted by the traffic sensors in Zurich) was obtained from ASTRA (Federal Roads Office). We used linear interpolation between measurements to match temperature and traffic density to the individual trials. 
honked, the number of blocked vehicles, the sex and estimated age of the driver, and the status indicated by the foremost blocked vehicle). All collected information was validated and complemented based on an analysis of the videos later on. For example, exact measurements of the horn-honking response times were obtained from the videos (in a few cases, the honking was not audible on the video, in which case we used the measurement taken in the field; the correlation between the measurements taken in the field and the videos is $r=0.98$ ). Based on stills from the videos, an automobile expert coded the exact make and model of the blocked car, its approximate production year, and its selling price.

In the analyses below we exclude a handful of observations because, for example, the approaching car turned into a parking spot instead of being blocked, or because information on some key variables was missing or inconsistent (due to the failure of the observers to take notes, or due to missing video recordings). We also exclude 10 observations because the blocked vehicle was a delivery van or motorcycle, for which a status comparison to the experimental car is difficult. In total, 106 valid cases are available for the analysis. In 10 cases, the honking response came from a successive vehicle instead of the foremost blocked car (detailed data was collected only for the foremost car). We treat these cases as censored in our analysis.

We use two measures for the status of the blocked vehicles: (a) a subjective classification in terms of one of three hierarchical categories similar to Experiment 1 (lower, middle, higher), and (b) the estimated monetary value of the vehicle. The monetary value is equal to the selling price after applying a yearly depreciation of $5 \%$. There is a clear relation between the two measures: the average monetary values are 16,497 CHF, 24,971 CHF, or 37,573 CHF for vehicles classified as lower, middle, or higher status.

\section{Data analysis}

Since there are censored response times, the techniques of event history modeling are the most appropriate statistical tools for analyzing the data (Diekmann et al. 1996:763). We use the product-limit method to estimate survival curves as descriptive measures. Multivariate analysis employs the semi-parametric Cox regression model (Cox 1972; Diekmann and Mitter 1984). In the Cox model, the hazard rate $r(t)$ of horn-honking (i.e., the probability of a horn-honking event at time $t$, conditional on its not having yet occurred) is modeled as the product of an unspecified baseline hazard rate and the exponent of a linear function of the covariates. In the following analysis we will report the exponents of the estimated coefficients, since they can be interpreted in a straightforward manner as multiplication effects on the hazard rate, that is, as hazard ratios (effects greater than one imply an increase in the hazard rate and faster honking reactions; effects lower than one imply a decrease in the hazard rate and slower honking reactions). The Cox regression assumes proportional hazards at each point in time. The applicability of this assumption was tested, and deviation from it was negligible for the models discussed below (see last row in Table 1). 


\section{Results}

Figure 1 shows the horn-honking survival functions from the two experiments. In Experiment 1 , the time-window in which a honking reaction could occur was restricted to 12 seconds. About 80 percent of all blocked drivers honked within these 12 seconds (i.e., the survival function drops down to about $20 \%$ ). In Experiment 2, there was no such restriction, as the blocking car remained stopped until the first honking reaction occurred (the maximum time recoded in our data is 60 seconds). In Figure 1, we only display the survival curve for the first 20 seconds, within which about $80 \%$ of the blocked subjects honked. Overall, honking reactions occurred faster in Experiment 1 than in Experiment 2. The reason is that in Experiment 2, reaction time was measured from when the blocked vehicle entered the street, whereas in Experiment 1, time was measured from the moment the lights turned green, with the blocked vehicle already in position behind the experimental car.

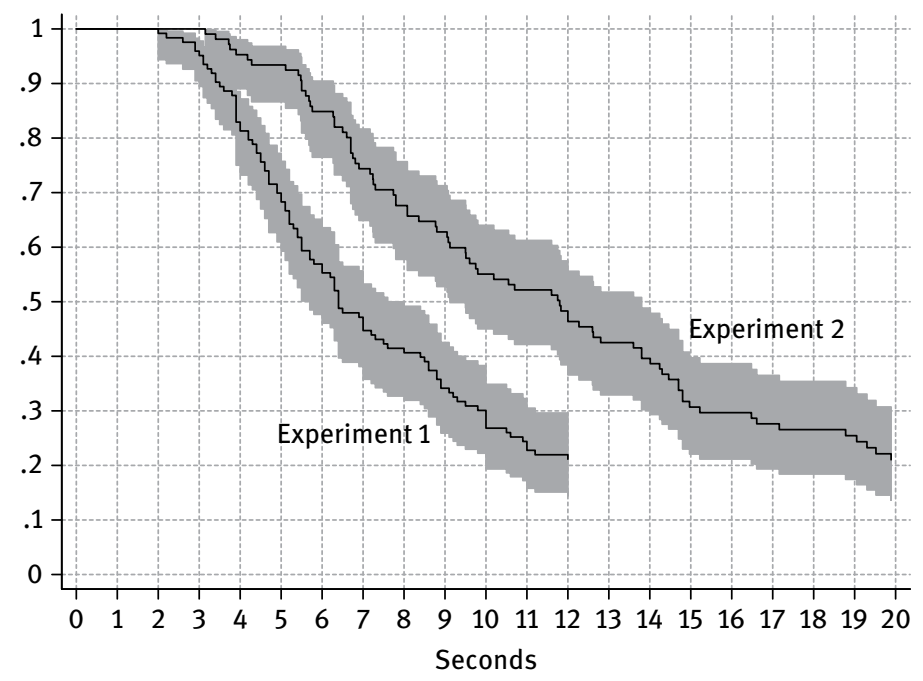

Fig. 1: Horn-honking survival functions.

To test our hypothesis that honking reactions are affected by the status difference between the experimental car and the blocked vehicle, Table 1 displays the results of several Cox regressions (for descriptive statistics, see Table 2 in the Appendix). In Model 1, which is based on the data of Experiment 1, we see that a status difference between the two vehicles accords with a significant increase in the hazard rate of honking: a onepoint status difference increases the hazard rate by about $40 \%$. The corresponding results from Experiment 2 (Model 3) are very similar (showing a significant increase in 
Tab. 1: Multivariate analysis of honking response times (z-values in brackets).

\begin{tabular}{|c|c|c|c|c|c|c|}
\hline & \multirow{2}{*}{\multicolumn{2}{|c|}{$\begin{array}{l}\text { Experiment } 1 \\
\text { Status }\end{array}$}} & \multicolumn{4}{|l|}{ Experiment 2} \\
\hline & & & Status & & Value & \\
\hline & Model 1 & Model 2 & Model 3 & Model 4 & Model 5 & Model 6 \\
\hline $\begin{array}{l}\text { Absolute difference in } \\
\text { status or value }^{\mathrm{a}}\end{array}$ & $\begin{array}{c}1.42^{*} \\
(2.16)\end{array}$ & & $\begin{array}{l}1.45^{*} \\
(2.44)\end{array}$ & & $\begin{array}{l}2.40^{* *} \\
(3.07)\end{array}$ & \\
\hline $\begin{array}{l}\text { Downward difference in } \\
\text { status or value }^{\text {a }}\end{array}$ & & $\begin{array}{l}1.11 \\
(0.46)\end{array}$ & & $\begin{array}{l}1.07 \\
(0.34)\end{array}$ & & $\begin{array}{l}2.99^{*} \\
(2.50)\end{array}$ \\
\hline $\begin{array}{l}\text { Upward difference in } \\
\text { status or value }^{\text {a }}\end{array}$ & & $\begin{array}{l}1.90^{*} \\
(2.57)\end{array}$ & & $\begin{array}{l}2.02^{* *} \\
(3.17)\end{array}$ & & $\begin{array}{l}2.11^{*} \\
(2.16)\end{array}$ \\
\hline $\begin{array}{l}\text { Status of experimental } \\
\text { car ( } 0 \text { low, } 1 \text { high) }\end{array}$ & $\begin{array}{l}1.15 \\
(0.67)\end{array}$ & $\begin{array}{c}0.67 \\
(-0.99)\end{array}$ & $\begin{array}{c}0.85 \\
(-0.71)\end{array}$ & $\begin{array}{r}0.46^{*} \\
(-2.08)\end{array}$ & $\begin{array}{r}0.52^{*} \\
(-2.23)\end{array}$ & $\begin{array}{c}0.66 \\
(-0.88)\end{array}$ \\
\hline $\begin{array}{l}\text { Driver in experimental } \\
\text { car is female }(0 / 1)\end{array}$ & & & $\begin{array}{l}0.52^{* *} \\
(-2.81)\end{array}$ & $\begin{array}{l}0.53^{* *} \\
(-2.69)\end{array}$ & $\begin{array}{c}0.51^{* *} \\
(-2.84)\end{array}$ & $\begin{array}{l}0.50^{* *} \\
(-2.91)\end{array}$ \\
\hline $\begin{array}{l}\text { Driver in blocked car is } \\
\text { female }(0 / 1)\end{array}$ & $\begin{array}{c}0.64 \\
(-1.64)\end{array}$ & $\begin{array}{r}0.55^{*} \\
(-2.08)\end{array}$ & $\begin{array}{c}1.61^{+} \\
(1.95)\end{array}$ & $\begin{array}{c}1.50^{+} \\
(1.66)\end{array}$ & $\begin{array}{r}1.50^{+} \\
(1.67)\end{array}$ & $\begin{array}{r}1.50^{+} \\
(1.68)\end{array}$ \\
\hline $\begin{array}{l}\text { Blocked driver aged } 18 \\
\text { through } 30(0 / 1)\end{array}$ & $\begin{array}{l}1.45 \\
(1.27)\end{array}$ & $\begin{array}{l}1.33 \\
(0.97)\end{array}$ & $\begin{array}{r}0.48^{*} \\
(-2.42)\end{array}$ & $\begin{array}{r}0.47^{*} \\
(-2.47)\end{array}$ & $\begin{array}{r}0.47^{*} \\
(-2.41)\end{array}$ & $\begin{array}{r}0.47^{*} \\
(-2.40)\end{array}$ \\
\hline $\begin{array}{l}\text { Blocked driver aged } 56 \\
\text { or older }(0 / 1)\end{array}$ & $\begin{array}{r}1.72^{*} \\
(2.07)\end{array}$ & $\begin{array}{r}1.78^{*} \\
(2.18)\end{array}$ & $\begin{array}{c}1.46 \\
(1.12)\end{array}$ & $\begin{array}{c}1.44 \\
(1.07)\end{array}$ & $\begin{array}{l}1.27 \\
(0.72)\end{array}$ & $\begin{array}{l}1.31 \\
(0.80)\end{array}$ \\
\hline Business vehicle $(0 / 1)$ & & & $\begin{array}{l}2.38^{*} \\
(2.01)\end{array}$ & $\begin{array}{c}2.05 \\
(1.64)\end{array}$ & $\begin{array}{r}2.28^{+} \\
(1.94)\end{array}$ & $\begin{array}{l}2.37^{*} \\
(2.00)\end{array}$ \\
\hline Temperature & & & $\begin{array}{l}1.13 \\
(0.75)\end{array}$ & $\begin{array}{c}1.24 \\
(1.25)\end{array}$ & $\begin{array}{l}1.18 \\
(0.99)\end{array}$ & $\begin{array}{l}1.16 \\
(0.91)\end{array}$ \\
\hline Traffic density & & & $\begin{array}{l}1.09 \\
(1.05)\end{array}$ & $\begin{array}{c}1.12 \\
(1.37)\end{array}$ & $\begin{array}{l}1.10 \\
(1.16)\end{array}$ & $\begin{array}{l}1.10 \\
(1.17)\end{array}$ \\
\hline $\begin{array}{l}\text { Direction of entry into } \\
\text { road ( } 0 \text { left, } 1 \text { right) }\end{array}$ & & & $\begin{array}{l}2.10^{* *} \\
(2.65)\end{array}$ & $\begin{array}{l}2.14^{* *} \\
(2.72)\end{array}$ & $\begin{array}{l}2.15^{* *} \\
(2.74)\end{array}$ & $\begin{array}{l}2.14^{* *} \\
(2.73)\end{array}$ \\
\hline Number of trials (events) & $123(97)$ & $123(97)$ & $106(96)$ & 106(96) & 106(96) & 106(96) \\
\hline Likelihood ratio $X^{2}(d f)$ & $13.5(5)^{*}$ & $16.0(6)^{*}$ & $26.4(10)^{* *}$ & $* \quad 31.0(11)^{* *}$ & $29.8(10)^{* *}$ & ** $30.2(11)^{* *}$ \\
\hline $\begin{array}{l}\text { Proportional-hazards } \\
\text { test ( } p \text {-value) }\end{array}$ & 0.784 & 0.800 & 0.414 & 0.476 & 0.640 & 0.728 \\
\hline
\end{tabular}

Notes: Displayed are hazard ratios from proportional-hazards models (Cox regressions). Reference age group: drivers aged 31 through 55 .

a Difference in status (0: same level, 1: low or high vs. middle, 2: low vs. high) (models 1-4) or difference in log value (models 5/6) between blocked vehicle and blocking vehicle. The difference is downward (upward) if the status/value of the blocked vehicle is higher (lower) than the status/value of the blocking vehicle.

${ }^{+} p<0.10, \quad{ }^{*} p<0.05, \quad{ }^{* *} p<0.01, \quad{ }^{* * *} p<0.001$. 
the hazard rate of about $45 \%$ for a one-point status difference). ${ }^{4}$ Furthermore, if the status difference is measured in terms of the difference in monetary value between the vehicles, we see a very clear and statistically significant effect (Model 5). Since we use a logarithmic specification, the coefficient of 2.40 can be interpreted as about a $2.40^{\ln (2)}-1=83 \%$ increase in the hazard rate if the higher status vehicle is worth about twice as much as the lower status vehicle, compared to a situation in which the value of both vehicles is the same.

Overall, these results provide clear evidence for the "difference hypothesis" (the hypothesis that sanctioning is exerted more readily if there is a status difference between the two actors). Also note that the above models fit the data significantly better than models in which the status or monetary value of the blocked vehicle is introduced as is, without taking differences to the status of the experimental car (not shown). To put it another way, the actors' status levels per se do not explain the patterns found in our data; it is the combination of status between the two actors that matters.

Against the backdrop of the literature discussed above, an interesting question is whether the effects work the same in both directions, or whether, for example, aggression mainly "flows downward". In Models 2, 4, and 6, the effects of the status difference are separated into an effect of a downward difference (the blocked driver has a higher status than the blocker) and an effect of an upward difference (the blocked driver has a lower status than the blocker). The results from Model 2 (Experiment 1) and Model 4 (Experiment 2) suggest that status matters when a lower status car is blocked by a higher status car, but not in the reverse case. These results suggest that aggression "flows upward", but the results are not fully conclusive, as the difference in effects of a downward difference and an upward difference is not statistically significant in Model 2 ( $p=0.119$ ) and only mildly significant in Model 4 ( $p=0.034)$. It is thus not entirely clear whether the distinction between downward and upward differences really matters. Furthermore, Model 6, in which status is measured in terms of the monetary value of the vehicles, does not provide support for such a distinction. Here, both effects are statistically significant, and the effect of a downward difference is in fact somewhat stronger (although the difference between the two effects is far from being statistically significant: $p=0.515$ ). The results from Model 6 thus suggest that the relationship between peer-punishment and status is similar in both situations.

For a better impression of the size of the discussed effects, Figure 2 displays the predicted survival curves from Models 2, 4, and 6 for different combinations of the

4 The status difference variable in these models can take on three values: 0 (same status category), 1 (difference between a middle status reactor and a lower or higher status experimental car), and 2 (difference between a higher status reactor and a lower status experimental car, or vice versa). Since the null hypothesis of a linear effect of the status difference (i.e., the effect of a one-point status difference is exactly half of the effect of a two-point status difference) cannot be rejected ( $p$-value of 0.893 for Model 1 and 0.601 for Model 3), we refrain from using a more complex specification with separate effects for the two levels of status difference. 
Low status blocker

Experiment 1 (status)

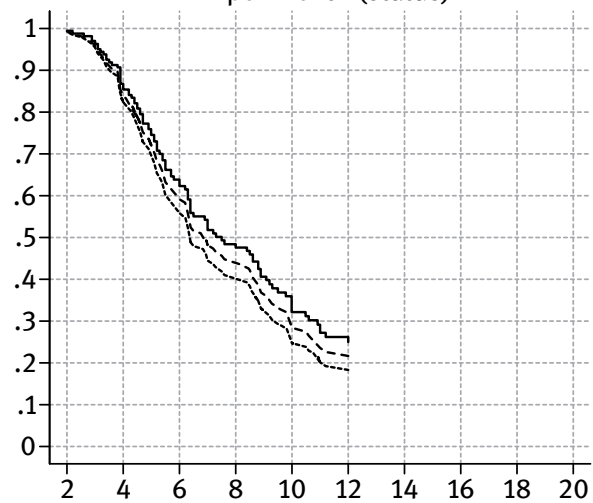

Experiment 2 (status)

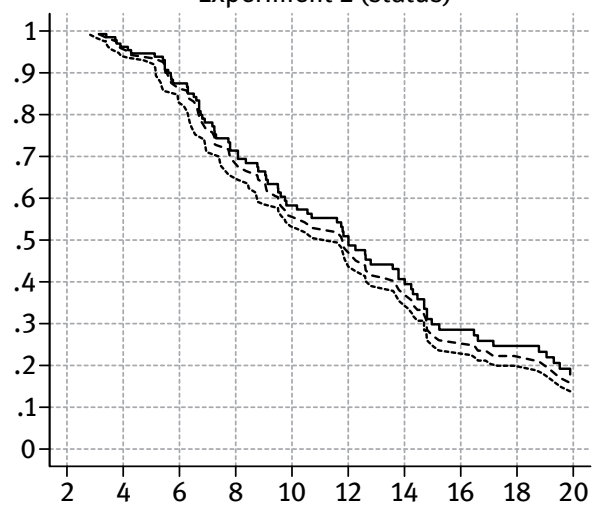

Experiment 2 (value)

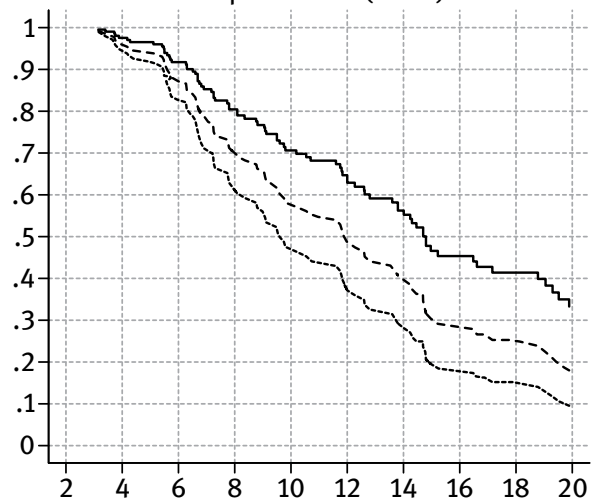

Difference: —_ Small ...... Medium ........... Large
High status blocker

Experiment 1 (status)

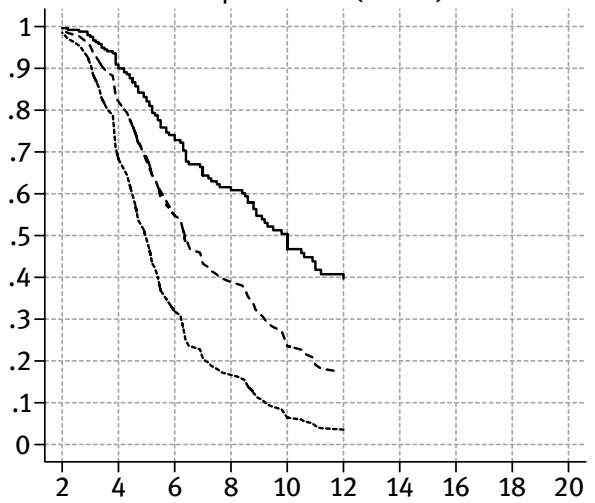

Experiment 2 (status)

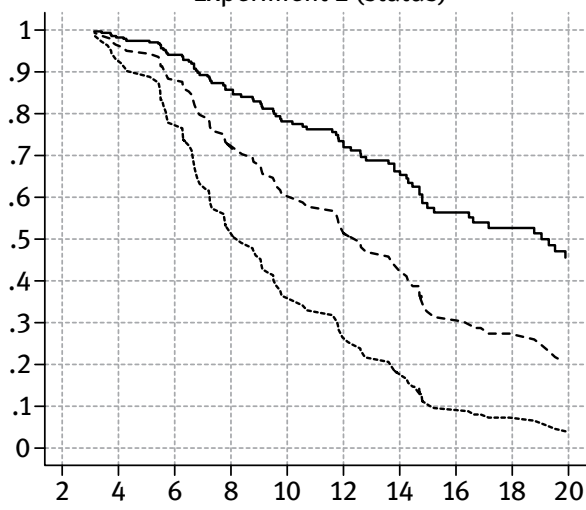

Experiment 2 (value)

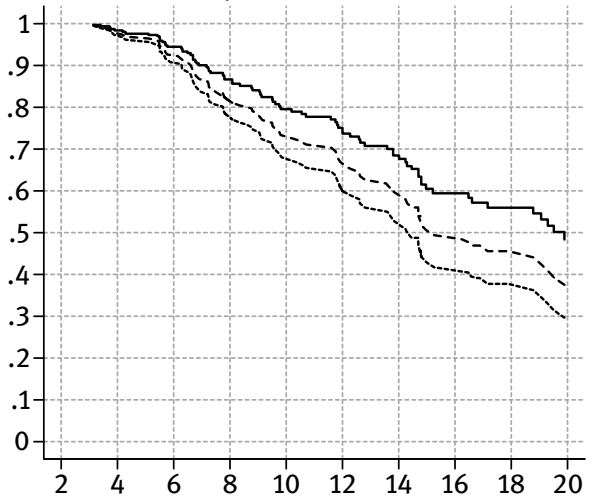

Fig. 2: Predicted survival functions by status or value difference from Models 2, 4, and 6. 
status of the experimental vehicle and the status of the blocked driver (with average values for the control variables). In the case of Model 2 (upper subgraphs) and Model 4 (middle subgraphs), the scenarios reflect the possible combinations of the categorical status variable (small difference: same category; medium difference: middle vs. low or high; large difference: low vs. high). In the case of Model 6 (lower subgraphs), the scenarios are determined by relative differences in monetary value (small difference: same value; medium difference: the value of one of the vehicles is $50 \%$ higher than the value of the other vehicle; large difference: one of the vehicles is worth twice as much as the other; these scenarios were chosen in accordance with the approximate differences in average vehicle values between the three status groups, for which see above). The subgraphs on the left illustrate the effect of a (downward) status difference in case of the lower status experimental car; the subgraphs on the right show the effect of an (upward) status difference in case of the upper status experimental car. In all cases larger status differences lead to lower survival curves: the larger the status difference, the more drivers honk their horn within a given timespan. In the upper two subgraphs on the left, the differences between the curves are negligible (and not statistically significant). In the other cases, however, the differences are substantial. For example, in Experiment 2, only about $20 \%$ honk within the first 10 seconds when both vehicles belong to the higher status class, but more than $60 \%$ of lower class drivers honk in the same timespan if they are blocked by a higher class vehicle (middle subgraph on the right). Correspondingly, the median response time (the time until $50 \%$ of the cars honked) is almost 20 seconds in the former case, but only 8 seconds in the later. For Experiment 1, the effects of an upward status difference are of similar magnitude (see the upper right subgraph). If status is measured in terms of vehicle value, the effects are substantial in both directions (see lower subgraphs), but the magnitude of the effects is somewhat smaller than above. Median response times for large and small differences were about 10 and 15 seconds in the case of the low status blocker, and about 14 and 20 seconds in the case of the high status blocker.

Note that the curves in the right subgraphs tend to be higher than the curves in the left subgraphs. This means that, controlling for status difference, an upper status experimental car elicited a somewhat slower honking responses than a lower status car. The corresponding coefficients (reflecting the difference between the solid lines on the left and on the right) point in the same direction in all three models, but only in Model 4 is the coefficient statistically significant. The evidence for a more generous treatment of high-status norm violators is therefore only weak.

With respect to the control variables, we find a clear effect of the sex of the driver of the experimental car. Hazard rates were substantially lower if the driver was female and not male (Models 4-6, Experiment 2 only; in Experiment 1 the driver was always male). With respect to the sex of the blocked driver, we found inconsistent results between the two experiments. In Experiment 1, females tended to have lower hazard rates than males, but in Experiment 2, females tended to show faster honking reac- 
tions (the effects, however, were only marginally significant)..$^{5}$ One may suspect that the combination of the genders of the two drivers matters. Adding an interaction term to the models of Experiment 2 did reveal a diminishing effect if both drivers were female, but the difference was far from being statistically significant ( $p$-values between 0.3 and 0.4 , depending on the model). In terms of the age of the blocked drivers, the results were also inconsistent between the experiments. Whereas older drivers in Experiment 1 had significantly higher hazard rates than middle-aged drivers, the corresponding effect was smaller and not significant in Experiment 2 (although pointing in the same direction). Furthermore, young drivers in Experiment 1 tended to have higher hazard rates (although this was not statistically significant), whereas younger drivers in Experiment 2 had significantly lower hazard rates than middle-aged drivers. For Experiment 2, for which more control variables are available, we found mild evidence for faster honking reactions in drivers of business vehicles. Temperature and traffic density had effects in the expected direction, but were not statistically significant. A clear effect, however, was found for the direction from which the blocked car entered the street. This is a purely technical effect related to the way in which we determined the starting point for measuring the honking response times. We also evaluated the effects of some further control variables, such as the color of the blocked car, without finding any meaningful results (not shown). ${ }^{6}$

\footnotetext{
5 Results from other studies on the relative willingness of males and females to sound their car horns are also ambiguous. While Doob and Gross (1968), Shinar (1998:149-150), and Shinar and Compton (2004) report significantly fewer honking responses by female drivers, the effect has not been significant in several replications of the horn-honking experiment (Chase and Mills 1973; Deaux 1971; Diekmann et al. 1996; Ellison et al. 1995; Forgas 1976; Kenrick and MacFarlane 1986; Shinar 1998:151156; Turner, Layton, and Simons 1975), although the results of most of these studies showed longer latencies for women. Hennessey and Wiesenthal (1999) find no differences between men and women in behaviors such as honking, but suggest in a later article (2001) that a more distinct difference between men and women may be expected in the case of "driver violence", that is, more severe forms of behavior, such as chasing other drivers or vandalizing vehicles. These results fit well with those reported for aggression in general. A meta-analysis by Bettencourt and Miller (1996) suggests that the largest differences between male and female aggression occur either in conditions in which there is no provocation, or when the aggression is expressed in physical form.

6 One variable, whether successive vehicles were present behind the blocked car, did have a significant effect (and including this variable also rendered the effect of traffic density significant). One could expect that the presence of successive vehicles is an additional stressor putting pressure on the blocked car, leading to faster honking reactions. Oddly, however, the effect was negative. We did not include this effect in our models because the result is an artifact of how the variable was measured. The longer a blocked driver refrained from honking, the higher the chance that additional vehicles appeared in the street (this also explains the increased effect of traffic density, as more cars appear in a given timespan if traffic density is high). Because the variable only measures whether additional vehicles were present, but not the exact times at which they appeared, the variable is endogenous to the honking behavior of the blocked driver. To estimate the effect of additional vehicles consistently, their appearance would have to be introduced in terms of a time-varying covariate.
} 


\section{Conclusions}

The findings reported in this paper provide evidence that the disparity in social status between two actors has a positive effect on the degree of sanctioning behavior that is expressed during their interaction. These results were obtained in two road-traffic field experiments, during which subjects' behavior was observed after their cars had been blocked by another car. Specifically, latencies in horn-honking responses were significantly higher in cases where the driver of a car was blocked by an experimental car of similar status than in cases where it was blocked by a car of quite different status. These results support our hypothesis. For the question of whether status differences operate in the same way irrespective of the direction of the difference (the punisher's status being higher than the norm violator's status, or vice versa), or whether sanctioning "flows downward" as suggested by literature on aggressive behavior, our findings are ambiguous. The results for one of our status measures suggests that sanctioning mainly "flows upward", counter to the expectation from the literature. However, the statistical evidence for a difference in the effect depending on direction is not particularly strong. Moreover, clearly symmetric effects were found for our second status measure.

Despite the fact that our results were obtained with a few deviations from previous experimental designs, they may reflect something more than the choice of a particular methodology, especially since similar results were obtained by Diekmann et al. (1996). The experimental car used to block the intersection by Diekmann et al. was classified as "lower middle class", which was also the class of blocked drivers who showed the lowest level of horn-honking in their experiment. The level of horn-honking increased monotonically for higher status classes, and also for the lower status class: that is, the larger the status difference, the higher the level of horn-honking. Whether similar social status may have contributed to the effects detailed in other previous studies is difficult to assess, since the status of the blocked car was not reported in those studies. However, according to the status-similarity hypothesis, the results of the classic hornhonking experiments described in the introduction should depend on the composition of the sample of blocked subjects. If there are, for example, predominantly high-status subjects in the sample, one would expect a lower-status blocking vehicle to elicit more aggressive responses than a higher-status car, as observed by Doob and Gross (1968) and Deaux (1971). If, on the other hand, the reactors are drivers of mostly low-status cars, one would expect more aggressive responses toward a higher-status blocking vehicle than to a lower-status blocking vehicle, as reported by Chase and Mills (1973).

The situation we study can be seen as a social dilemma in the sense that individual behavior (blocking the road) has negative externalities for the public (impediment of traffic flow), and that the blocking car violates a social norm (to keep the road clear if possible). Most likely, however, there is no second-order dilemma with respect to the enforcement of norm compliance, as most of the externalities are imposed on a single 
actor (the blocked driver). It is reasonable to assume that the costs of sanctioning are much lower than the benefits, even though there may be a small chance that the norm violator will engage in retaliatory behavior rather than move the car. Nonetheless, our study is a valuable contribution to the literature on peer-punishment, as it shows how punishing behavior depends on the social status of the actors. We are, however, skeptical about whether our results can be applied to situations in which status is more than a mere token of social categorization. As discussed in the introduction, different results may, for example, be expected in a situation characterized by competition for status positions, or in a situation where an explicit power relationship exists between actors of different status. How status relates to sanctioning in different types of situations is an interesting question to be studied in future research.

\section{Appendix}

Tab. 2: Descriptive statistics of the predictors.

\begin{tabular}{|c|c|c|c|c|}
\hline & \multicolumn{2}{|c|}{ Experiment 1} & \multicolumn{2}{|c|}{ Experiment 2} \\
\hline & Mean & Std. dev. & Mean & Std. dev. \\
\hline Status of blocker (0 low, 1 high) & 0.496 & & 0.481 & \\
\hline Driver in blocking car is female $(0 / 1)$ & & & 0.528 & \\
\hline \multicolumn{5}{|l|}{ Status of blocked vehicle } \\
\hline- low & 0.252 & & 0.368 & \\
\hline - middle & 0.553 & & 0.387 & \\
\hline - high & 0.195 & & 0.245 & \\
\hline Absolute difference in status (0-2) & 0.976 & 0.671 & 0.972 & 0.786 \\
\hline Downward difference in status (0-2) & 0.463 & 0.669 & 0.443 & 0.705 \\
\hline Upward difference in status (0-2) & 0.512 & 0.694 & 0.528 & 0.771 \\
\hline $\begin{array}{l}\text { Natural logarithm of value of blocked vehicle } \\
\text { (selling price minus } 5 \% \text { depreciation per year) }\end{array}$ & & & 10.02 & 0.451 \\
\hline Absolute difference in log value & & & 0.792 & 0.497 \\
\hline Downward difference in log value & & & 0.259 & 0.363 \\
\hline Upward difference in log value & & & 0.533 & 0.627 \\
\hline Female blocked driver (0/1) & 0.236 & & 0.349 & \\
\hline \multicolumn{5}{|l|}{ Estimated age of blocked driver } \\
\hline-18 through 30 & 0.138 & & 0.406 & \\
\hline - 31 through 55 & 0.650 & & 0.462 & \\
\hline-56 or older & 0.211 & & 0.132 & \\
\hline Business vehicle $(0 / 1)$ & & & 0.075 & \\
\hline Temperature (in degree Celsius) & & & 28.19 & 0.984 \\
\hline Traffic density (in 1000 vehicles per hour) & & & 11.64 & 2.214 \\
\hline Direction of entry into road (0 left, 1 right) & & & 0.764 & \\
\hline Number of observations & 123 & & 106 & \\
\hline
\end{tabular}




\section{Bibliography}

[1] Allan, Steven, and Paul Gilbert. 2002. "Anger and anger expression in relation to perceptions of social rank, entrapment and depressive symptoms." Personality and Individual Differences 32(3):551-565.

[2] Anderson, Cameron, and Jennifer L. Berdahl. 2002. "The experience of power: Examining the effects of power on approach and inhibition tendencies." Journal of Personality and Social Psychology 83(6):1362-1377.

[3] Anderson, Craig A., and Brad J. Bushman. 2002. "Human aggression." Annual Review of Psychology 53:27-51.

[4] Baron, Robert A. 1976. "The reduction of human aggression: A field study of the influence of incompatible reactions." Journal of Applied Social Psychology 6(3):260-274.

[5] Barroso, F. G., C. L. Alados, and J. Boza. 2000. "Social hierarchy in the domestic goat: effect on food habits and production." Applied Animal Behaviour Science 69(1):35-53.

[6] Bettencourt, B. Ann, and Norman Miller. 1996. "Gender differences in aggression as a function of provocation: A meta-analysis." Psychological Bulletin 119(3):422-447.

[7] Billig, Michael, and Henri Tajfel. 1973. "Social categorization and similarity in intergroup behaviour." European Journal of Social Psychology 3(1):9-26.

[8] Brewer, Marilynn B. 1979. "In-group bias in the minimal intergroup situation: A cognitivemotivational analysis." Psychological Bulletin 86(2):307-324.

[9] Brewer, Marilynn B., and Roderick M. Kramer. 1985. "The psychology of intergroup attitudes and behavior." Annual Review of Psychology 36:219-243.

[10] Burger, Jerry M., and Harris M. Cooper. 1979. "The desirability of control." Motivation and Emotion 3(4):381-393.

[11] Chase, Lawrence J., and Norbert H. Mills. 1973. "Status of frustrator as a facilitator of aggression: A brief note." The Journal of Psychology 84(2):225-226.

[12] Clark, Candace. 1990. "Emotions and micropolitics in everyday life: Some patterns and paradoxes of 'place'." Pp. 505-533 in Research agendas in the sociology of emotions, edited by T. D. Kemper. Albany, NY: State University of New York Press.

[13] Conway, Michael R., Roberto DiFazio, and Shari Mayman. 1999. "Judging others' emotions as a function of others' status." Social Psychology Quarterly 62(3):291-305.

[14] Cox, David R. 1972. "Regression models and life-tables." Journal of the Royal Statistical Society, Series B 34:187-220.

[15] Deaux, Kay K. 1971. "Honking at the intersection: A replication and extension." The Journal of Social Psychology 84(1):159-160.

[16] Deffenbacher, Jerry L., Rebekah S. Lynch, Eugene R. Oetting, and David A. Yingling. 2001. "Driving anger: correlates and a test of state-trait theory." Personality and Individual Differences 31(8):1321-1331.

[17] Deffenbacher, Jerry L., Eugene R. Oetting, and Rebekah S. Lynch. 1994. "Development of a driving anger scale." Psychological Reports 74(1):83-91.

[18] Diekmann, Andreas, Monika Jungbauer-Gans, Heinz Krassnig, and Sigrid Lorenz. 1996. "Social status and aggression: A field study analyzed by survival analysis." Journal of Social Psychology 136(6):761-768.

[19] Diekmann, Andreas, and Peter Mitter. 1984. Methoden zur Analyse von Zeitverläufen. Anwendungen stochastischer Prozesse bei der Untersuchung von Ereignisdaten. Stuttgart: B. G. Teubner.

[20] Doob, Anthony N., and Alan E. Gross. 1968. "Status of frustrator as an inhibitor of hornhonking responses.” The Journal of Social Psychology 76(2):213-218. 
[21] Ellison, Patricia A., John M. Govern, Herbert L. Petri, and Michael H. Figler. 1995. “Anonymity and aggressive driving behavior: A field study." Journal of Social Behavior and Personality 10(1):265-272.

[22] Forgas, Joseph P. 1976. "An unobtrusive study of reactions to national stereotypes in four European countries.” The Journal of Social Psychology 99(1):37-42.

[23] Gould, Roger V. 2003. Collision of Wills: How ambiguity about social rank breeds conflict. Chicago, IL: University of Chicago Press.

[24] Galinsky, Adam D., Deborah H. Gruenfeld, and Joe C. Magee. 2003. "From power to action." Journal of Personality and Social Psychology 85(3):453-466.

[25] Haukkala, Ari. 2002. "Socio-economic differences in hostility measures: A population based study." Psychology and Health 17(2):191-202.

[26] Hecht, Marvin A., and Marianne LaFrance. 1988. "License or obligation to smile: The effect of power and gender on amount and type of smiling." Personality and Social Psychology Bulletin 24(12):1326-1336.

[27] Hennessy, Dwight A., and David L. Wiesenthal. 1997. "The relationship between traffic congestion, driver stress and direct versus indirect coping behaviours." Ergonomics 40(3):348-361.

[28] Hennessy, Dwight A., and David L. Wiesenthal. 1999. "Traffic congestion, driver stress, and driver aggression.” Aggressive Behavior 25(6):409-423.

[29] Hennessy, Dwight A., and David L. Wiesenthal. 2001. “Gender, driver aggression, and driver violence: An applied evaluation.” Sex Roles 44(11-12):661-676.

[30] Jann, Ben, Stephan Suhner, and Renato Marioni. 1995. Sozialer Status und “Hupzeiten”. Ergebnisse aus einem Feldexperiment. University of Bern: Mimeo.

[31] Jann, Ben. 2009. "Sozialer Status und Hup-Verhalten. Ein Feldexperiment zum Zusammenhang zwischen Status und Aggression im Strassenverkehr.” Pp. 397-410 in Klein aber fein! Quantitative empirische Sozialforschung mit kleinen Fallzahlen, edited by P. Kriwy, and C. Gross. Wiesbaden: VS-Verlag.

[32] Keltner, Dacher, Deborah H. Gruenfeld, and Cameron Anderson. 2003. "Power, approach, and inhibition." Psychological Review 110(2):265-284.

[33] Kemper, Theodore D. 1978. A social interaction theory of emotions. New York: Wiley.

[34] Kemper, Theodore D. 1987. "How many emotions are there? Wedding the social and the autonomic components.” American Journal of Sociology 93(2):263-289.

[35] Kenrick, Douglas T., and Steven W. MacFarlane. 1986. "Ambient temperature and horn honking: A field study of the heat/aggression relationship." Environment and Behavior 18(2):179191.

[36] Knapper, Christopher K., and Arthur J. Cropley. 1980. “Interpersonal factors in driving." International Review of Applied Psychology 29(4):415-438.

[37] Kramer, Roderick M., and Marilynn B. Brewer. 1986. "Social group identity and the emergence of cooperation in resource conservation dilemmas." Pp. 205-234 in Experimental social dilemmas, edited by H. A. M. Wilke, D. M. Messick, and C. G. Rutte. Frankfurt am Main: Peter Lang.

[38] Kuppens, Peter, Iven Van Mechelen, and Michel Meulders. 2004. "Every cloud has a silver lining: Interpersonal and individual differences determinants of anger-related behaviors.” Personality and Social Psychology Bulletin 30(12):1550-1564.

[39] Lajunen, Timo, and Dianne Parker. 2001. “Are aggressive people aggressive drivers? A study of the relationship between self-reported general aggressiveness, driver anger and aggressive driving." Accident Analysis and Prevention 33(2):243-255.

[40] Lajunen, Timo, Dianne Parker, and Stephen G. Stradling. 1998. "Dimensions of driver anger, aggressive and highway code violations and their mediation by safety orientation in UK drivers." Transportation Research Part F 1:107-121. 
[41] Lawton, Rebecca, and Amanda Nutter. 2002. "A comparison of reported levels and expression of anger in everyday and driving situations." British Journal of Psychology 93(3):407-423.

[42] Lively, Kathryn J. 2000. "Reciprocal emotion management: Working together to maintain stratification." Work and Occupations 27(1):32-63.

[43] Lovaglia, Michael J., and Jeffrey A. Houser. 1996. "Emotional reactions and status in groups." American Sociological Review 61(5):869-883.

[44] Marsh, Peter, and Peter Collett. 1986. Driving passion: The psychology of the car. London: Jonathan Cape.

[45] McGarva, Andrew R., and Michelle Steiner. 2000. "Provoked driver aggression and status: A field study." Transportation Research Part F 3:167-179.

[46] McKinnon, Neil J. 1994. Symbolic interactionism as affect control. Albany, NY: State University of New York Press.

[47] Mummendey, Amélle, and Hans-Joachim Schreiber. 1983. "Better or just different? Positive social identity by discrimination against, or by differentiation from outgroups." European Journal of Social Psychology 13(4):389-397.

[48] Novaco, Raymond W. 1991. “Aggression on Roadways." Pp. 253-326 in Targets of Violence and Aggression, edited by R. Baenninger. Amsterdam: Elsevier Science Publishers.

[49] Parker, Dianne, Timo Lajunen, and Heikki Summala. 2002. "Anger and aggression among drivers in three European countries." Accident Analysis and Prevention 34(2):229-235.

[50] Pitkänen, Lea. 1973. "An aggression machine: Il. Interindividual differences in the aggressive defence responses aroused by varying stimulus conditions." Scandinavian Journal of Psychology 14(2):65-74.

[51] Ramirez, J. Martin, Carmen Santisteban, Takehiro Fujihara, and Stephanie Van Goozen. 2002. "Differences between experience of anger and readiness to angry action: A study of Japanese and Spanish students." Aggressive Behavior 28(6):429-438.

[52] Ridgeway, Cecilia, and Cathryn Johnson. 1990. "What is the relationship between socioemotional behavior and status in task groups?" American Journal of Sociology 95(5):1189-1212.

[53] Robinson, W. Peter. 1996. Social groups and identities. Developing the legacy of Henri Tajfel. Oxford: Butterworth-Heinemann.

[54] Rothe, Jörg, and Heiko Schmiedeskamp. 2006. Aggressionsverhalten im Strassenverkehr: Analyse der Hupverzögerung von blockierten Autos. ETH Zurich: Mimeo.

[55] Schieman, Scott. 2003. "Socioeconomic status and the frequency of anger across the life course.” Sociological Perspectives 46(2):207-222.

[56] Shinar, David. 1998. "Aggressive driving: The contribution of the drivers and the situation." Transportation Research Part F 1:137-160.

[57] Shinar, David, and Richard Compton. 2004. "Aggressive driving: an observational study of driver, vehicle, and situational variables." Accident Analysis and Prevention 36(3):429-437.

[58] Sloan, Melissa M. 2004. "The effects of occupational characteristics on the experience and expression of anger in the workplace." Work and Occupations 31(1):38-72.

[59] Smith-Lovin, Lynn. 1990. "Emotion as the confirmation and disconfirmation of identity: An affect control model." Pp. 238-270 in Research agendas in the sociology of emotions, edited by T. D. Kemper. Albany, NY: State University of New York Press.

[60] Tajfel, Henri. 1978. Differentiation between social groups. Studies in the social psychology of intergroup relations. London: Academic Press.

[61] Tajfel, Henri. 1982a. "Social psychology of intergroup relations." Annual Review of Psychology 33:1-39.

[62] Tajfel, Henri. 1982b. Social identity and intergroup relations. Cambridge: Cambridge University Press. 
[63] Tajfel, Henri, Michael G. Billig, R. P. Bundy, and Claude Flament. 1971. "Social Categorization and intergroup behaviour." European Journal of Social Psychology 1(2):149-177.

[64] Taubman-Ben-Ari, Orit, Mario Mikulincer, and Omri Gillath. 2004. "The multidimensional driving style inventory: Scale construction and validation." Accident Analysis and Prevention 36:323-332.

[65] Tiedens, Larissa Z. 2001. "Anger and advancement versus sadness and subjugation: The effect of negative emotion expressions on social status conferral." Journal of Personality and Social Psychology 80(1):86-94.

[66] Tiedens, Larissa Z., Phoebe C. Ellsworth, and Batja Mesquita. 2000. "Stereotypes about sentiments and status: Emotional expectations for high- and low-status group members.” Personality and Social Psychology Bulletin 26(5):560-574.

[67] Turner, Charles W., John F. Layton, and Lynn S. Simons. 1975. "Naturalistic studies of aggressive behavior: Aggressive stimuli, victim visibility, and horn honking." Journal of Personality and Social Psychology 31(6):1098-1107.

[68] Turner, John C., Rupert J. Brown, and Henri Tajfel, 1979. "Social comparison and group interest in ingroup favouritism." European Journal of Social Psychology 9(2):187-204.

[69] Verona, Edelyn, Christopher J. Patrick, and Alan R. Lang. 2002. "A direct assessment of the role of state and trait negative emotion in aggressive behavior." Journal of Abnormal Psychology 111(2):249-258.

[70] Yagil, Dana. 2001. “Interpersonal antecedents of drivers' aggression." Transportation Research Part F 4:119-131.

[71] Yazawa, Hisashi. 2004. "Effects of inferred social status and a beginning driver's sticker upon aggression of drivers in Japan." Psychological Reports 94(3):1215-1220. 
Brought to you by | Universitätsbibliothek Bern Authenticated | ben.jann@soz.unibe.ch Download Date | 11/6/17 11:35 AM 